02

\title{
Радиотермолюминесценция оксидных наноструктур на поверхности радиационно окисленных алюминия и бериллия
}

\author{
(C) Н.Н. Гаджиева, А.М. Магеррамов \\ Институт радиационных проблем НАН Азербайджана, \\ AZ 1141 Баку, Азербайджан \\ e-mail: nushaba6@mail.ru
}

Поступила в редакцию 27.10.2017 г.

\begin{abstract}
Методом радиотермолюминесценции изучена динамика формирования оксидных наноструктур на поверхностях окисленных алюминия и бериллия с водой при комнатной температуре и при радиационном воздействии. Рассмотрена роль промежуточных поверхностно-активных частиц в динамике изменений процесса окисления алюминия и бериллия в области поглощенной дозы $0.5-120 \mathrm{kGy}$. Установлено, что при формировании наноструктурных пленок основную роль играют молекулярный кислород и другие кислородсодержащие ион-радикальные группы, генерированные гамма-облучением. Изучена кинетика радиационного окисления алюминия и бериллия и выявлена их хемосорбционная пассивация. Обсужден возможный механизм данного процесса.
\end{abstract}

DOI: $10.21883 /$ OS.2018.03.45653.249-17

\section{Введение}

Приповерхностный слой металлов находится в особом физико-химическом состоянии. Он в значительной степени насыщен структурными дефектами (вакансии, дислокации, примеси), и его свойства отличаются от свойств объемного металла [1-5]. Особое состояние приповерхностных слоев может оказывать влияние на кинетику различных процессов, в том числе на диффузию, адсорбцию и радиолиз молекул воды. Контакт и взаимодействие воды с поверхностью металлов приводит к их изменению и сопровождается образованием оксидного слоя. При этом на поверхности формируется гетеросистема $\mathrm{Me}-\mathrm{MeO}$, что играет определяющую роль в радиационно стимулированных процессах с участием воды на поверхности металлов. Изучение начальной стадии образования и формирования поверхностных оксидных наноструктур имеет принципиальное значение для решения проблем пассивации поверхности и предопределяет ход процесса радиационной коррозии $[4,6,7]$.

При этом представляется важным выяснение роли релаксирующих промежуточно-активных частиц разложения воды в гетерогенной системе Ме/адс. $\mathrm{H}_{2} \mathrm{O}$ под действием $\gamma$-излучения. Для комплексного решения этих вопросов нами использованы метод детектирования, основанный на измерении электропроводности металла, позволяющий контролировать поведение хемосорбированных частиц с помощью наблюдения его электрофизических свойств, и ИК спектроскопический метод зондирования, позволяющий одновременно прослеживать формирование оксидного слоя и образование адсорбционноактивных поверхностных функциональных групп [8-10]. В настоящей работе нами применен метод радиотермолюминесценции (РТЛ) для изучения образования оксидных наноструктур на поверхности алюминия и бериллия при радиационном окислении в контакте с водой и установления роли кислородных дырочных центров, генерируемых $\gamma$-облучением и способных мигрировать в объем металла, и других кислородсодержащих групп в динамике формирования оксидных наноструктур.

\section{Экспериментальная часть}

В качестве объектов исследовали пластинки алюминия и бериллия размером $20 \times 10 \times 2 \mathrm{~mm}$. Пластинки алюминия марки АД-00 получены поэтапным прессованием цилиндрических гранул $\mathrm{Al}$ диаметром $3 \mathrm{~mm}$ и высотой $6 \mathrm{~mm} \mathrm{c} \mathrm{помощью} \mathrm{специальной} \mathrm{пресс-формы,}$ предназначенной для оптических исследований [6]. Шлифованные и полированные пластинки бериллия изготовлены из слитка Ве [8]. Пластинки имели гладкую поверхность с $R=0.80 \pm 0.05$ в средней ИК области длин волн $(15-2.2 \mu \mathrm{m})$.

$\mathrm{C}$ целью исключения примесных загрязнений образцы обрабатывали растворителями (этиловым спиртом, ацетоном) и промывали дистиллированной водой. Образцы предварительно высушивали при комнатной температуре в аргоне. Для дегидроксилирования поверхности и полной очистки от органических загрязнений образцы помещали в кварцевые ячейки и проводили дополнительную термообработку при $673 \mathrm{~K}$ в вакууме $\left(P=10^{-6} \mathrm{~Pa}\right)$ в течение $6 \mathrm{~h}$. Адсорбатом служили ненасыщенные пары бидистиллированной воды, из которой посторонние газы удаляли многократным вымораживанием в ловушке с жидким азотом с последующей откачкой. Адсорбцию $\mathrm{H}_{2} \mathrm{O}$ изучали по методике, описанной в $[9,10]$.

Радиационное окисление в гетеросистемах $\mathrm{Al}(\mathrm{Be}) / \mathrm{ads} . \mathrm{H}_{2} \mathrm{O}$ проводили при комнатной температуре $(300 \mathrm{~K})$. Образцы облучали на изотопном источнике ${ }^{60} \mathrm{Co} \mathrm{с} \mathrm{мощностью} \mathrm{дозы} d \Phi_{\gamma} / d t=1.03 \mathrm{~Gy} \cdot \mathrm{s}^{-1}$. Погло- 
щенная доза, определяемая ферросульфатным дозиметром, варьировалась в пределах $\Phi_{\gamma}=0.5-120 \mathrm{kGy}[11]$.

Кривые РТЛ получали на термолюминографе ТЛГ-69M в диапазоне температур 80-500 K при скорости разогрева $0.08 \mathrm{~K} \cdot \mathrm{s}^{-1}$. Для РТЛ анализа образцы дополнительно облучали дозой $10 \mathrm{kGy}$ при температуре $77 \mathrm{~K}$. Энергию активации рассчитывали по формуле, предложенной в [12].

Толщина оксидных пленок составляла от 8 до 250 и $125 \mathrm{~nm}$ для $\mathrm{Al}$ и Ве соответственно. Малые толщины оксидных пленок оценивали по формуле Стромейера [13] применительно к рентгено-фотоэлектронным спектрам, а относительно большие толщины определяли гравиметрическим методом.

\section{Обсуждение результатов}

Облучение $\gamma$-квантами при температуре $77 \mathrm{~K}$ радиационно окисленных алюминиевых пластинок в контакте с водой приводит к появлению ряда пиков РТЛ при температурах 170, 220 и $320 \mathrm{~K}$ (рис. 1, кривая 1). Низкотемпературный пик при $170 \mathrm{~K}$ с энергией активации $E_{a}=0.38 \mathrm{eV}$ может быть связан с термостимулированной люминесценцией хемосорбированного кислорода. Согласно [12], кислородный пик в области 150-170 K, обусловленный растворенным кислородом и другими кислородсодержащими газами, был обнаружен также при радиационном возбуждении термолюминесценции в полимерах. Интенсивность пика с максимумом при $170 \mathrm{~K}$ сильно зависит от времени контакта алюминия с водой при $\gamma$-облучении в системе $\mathrm{Al} / \mathrm{ads} . \mathrm{H}_{2} \mathrm{O}$, т. е. от толщины радиационно окисленной пленки. С увеличением этой толщины от $8 \mathrm{~nm}$ до $0.250 \mu \mathrm{m}$ интенсивность пика увеличивается в $\sim 6$ раз и появляется другой пик при $175 \mathrm{~K}$ с энергией активации $0.42 \mathrm{eV}$. Асимметричный пик при $220 \mathrm{~K}$ также расщепляется на два сравнительно узких пика, причем пик при $320 \mathrm{~K}$ фактически не изменяется (рис. 1, кривые 2,3). По-видимому, узкий пик при $T=175 \mathrm{~K}$ связан с термостимулированной адсорболюминесценцией молекулярного кислорода продукта радиационно-гетерогенного разложения воды на поверхностно-локализованных дырочных центрах типа $\mathrm{O}^{-}$[13-15]. В пользу этого свидетельствуют как разгорание люминесценции пика при $175 \mathrm{~K}$ после дополнительной адсорбции высушенного $\mathrm{O}_{2}$ в ячейке с исследуемой системой, так и ее тушение после длительной откачки данной системы при $T \geq 773 \mathrm{~K}$. Эмиссия электронов, сопровождаемая свечением в видимой области спектра, при адсорболюминесценции кислорода на алюминии наблюдалась и авторами [14-17]. Адсорбция кислорода на дырочных центрах в оксиде алюминия $\left(\mathrm{Al}_{2} \mathrm{O}_{3}\right)$ обнаружена также методами ЭПР (холодный сигнал $\left.g_{\text {cp }}=2.009\right)$, фото- и термодесорбции и термолюминесценции [14].

Пики при 195 и $230 \mathrm{~K}$ с энергиями активации 0.50 и $0.65 \mathrm{eV}$ принадлежат гидроксидам алюминия. Обра-

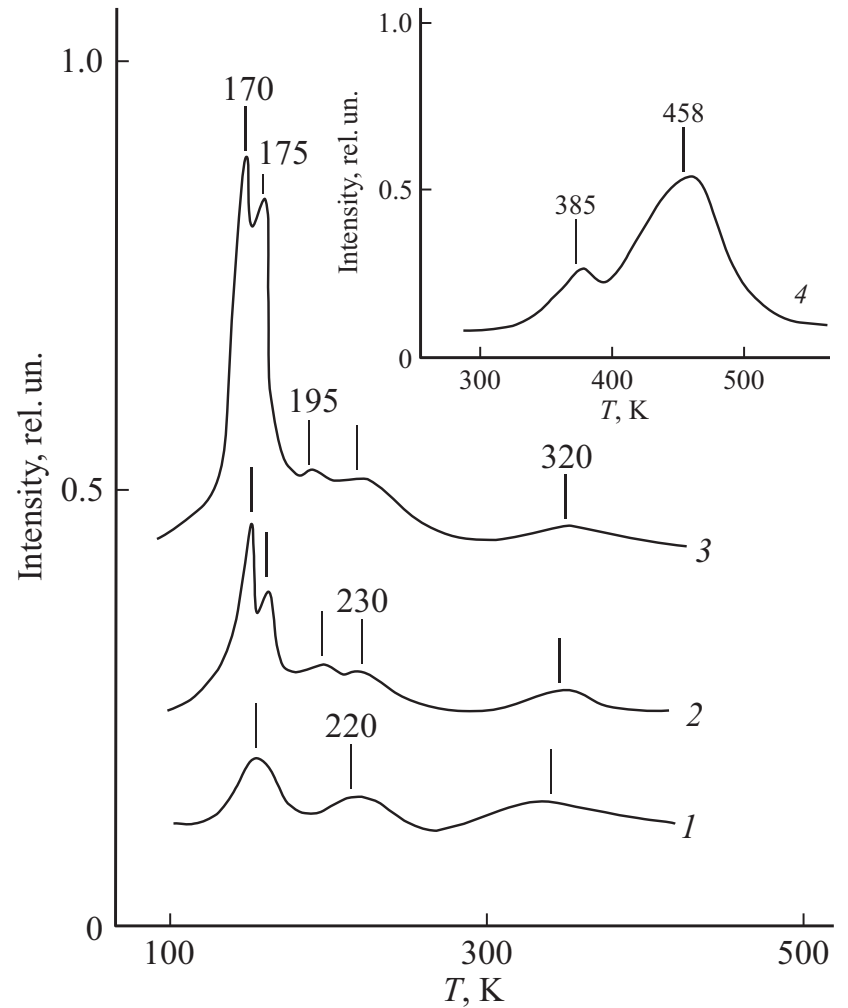

Рис. 1. Изменение кривых РТЛ оксидных пленок в зависимости от времени контакта алюминия с водой при радиационном окислении Al: $2 \min (1), 5 \mathrm{~h}(2), 20 \mathrm{~h}$ (3), 25 days (вставка, 4). $T=300 \mathrm{~K}, d \Phi_{\gamma} / d t=1.03 \mathrm{~Gy} \cdot \mathrm{s}^{-1}$.

зование различных гидроксидов подтверждается и ИК спектрами отражения [10,18]. Размытый пик с максимумом при $\sim 320 \mathrm{~K}$ с энергией активации $0.8-1.0 \mathrm{eV}$ обусловлен термостимулированной люминесценцией хемосорбированного кислорода и других кислородсодержащих групп $\left(\mathrm{OH}^{-}\right)$на поверхностных электронных $F^{+}$ и $F$-центрах. При идентификации пиков РТЛ мы основывались на экспериментальных данных о взаимодействии воды с поверхностью металлов из работ [10,14-17].

Таким образом, зондирование молекулярным кислородом - продуктом радиолиза $\mathrm{H}_{2} \mathrm{O}$ в сочетании с анализом спектров термостимулированной адсорболюминесценции - позволяет определить структуру радиационно-генерированных центров и связать сосуществующие формы адсорбированных молекул с определенными центрами. Основная часть адсорбции кислорода и кислородсодержащих групп протекает с участием поверхностных дырочных центров и участвует при образовании и формировании нанооксидных пленок. Образование и формирование нанооксидных пленок исследовалось и контролировалось нами также методами ИК спектроскопии и АСМ-микроскопии $[10,18]$. При этом на основе электрофизических исследований установлена многостадийность протекания процесса радиационного окисления и формирования нанооксидных пленок на поверхности $\mathrm{Al}$ и $\mathrm{Be}[8,18,19]$. 
Параметры РТЛ нанооксидных пленок на поверхности алюминия и бериллия

\begin{tabular}{|c|c|c|c|c|}
\hline № & Образец & $\begin{array}{r}\text { Температура } \\
\text { пиков РТЛ, К }\end{array}$ & $\begin{array}{c}\text { Энергия } \\
\text { активации } \\
\text { пиков РТЛ, eV }\end{array}$ & $\begin{array}{c}\text { Толщина } \\
\text { нанооксидных } \\
\text { пленок, nm }\end{array}$ \\
\hline 1 & $\begin{array}{l}\text { Нанооксидные } \\
\text { пленки алюминия }\end{array}$ & $\begin{array}{l}170 \\
175 \\
195 \\
230 \\
320\end{array}$ & $\begin{array}{c}0.38 \\
0.42 \\
0.50 \\
0.65 \\
0.8-1.0\end{array}$ & $8-250$ \\
\hline 2 & $\begin{array}{l}\text { Нанооксидные } \\
\text { пленки бериллия }\end{array}$ & $\begin{array}{c}90 \\
120 \\
190 \\
310\end{array}$ & $\begin{array}{l}0.14 \\
0.26 \\
0.38 \\
0.8\end{array}$ & $6-125$ \\
\hline
\end{tabular}

Следует отметить, что с утолщением оксидных пленок электронные центры $\left(F^{+}, F\right)$ сами могут становиться центрами хемосорбции кислорода. Однако образование связи $F^{+}$-центра с кислородом ведет к ослаблению люминесценции как через уменьшение концентрации $F^{+}$-центров, так и вследствие растущей безызлучательной релаксации, что и наблюдается в спектрах РТЛ.

Аналогичная картина получается также при изучении РТЛ радиационно окисленных бериллиевых пластинок в контакте с водой. Так, облучение $\gamma$-квантами при $77 \mathrm{~K}$ приводит к появлению ряда пиков РТЛ при температурах 90, 190 и $310 \mathrm{~K}$ (рис. 2, кривая 1). Низкотемпературный пик при $90 \mathrm{~K}$ с энергией активации $0.14 \mathrm{eV}$ связан с термостимулированной люминесценцией адсорбированного молекулярного кислорода на электронных центрах [17]. Интенсивность пика с максимумом при $90 \mathrm{~K}$ сильно зависит от времени контакта бериллия (или же от толщины радиационно окисленной пленки) с водой при $\gamma$-облучении в системе Be/ads. $\mathrm{H}_{2} \mathrm{O}$. C увеличением этой толщины на порядок (от 6 до $125 \mathrm{~nm}$ ) интенсивность пика увеличивается в $\sim 2$ раза и появляется другой пик при $120 \mathrm{~K}$ с энергией активации $0.26 \mathrm{eV}$. По-видимому, узкий пик при $120 \mathrm{~K}$ связан с адсорболюминесценцией молекулярного кислорода на поверхностно-локализованных дырочных центрах типа $\mathrm{O}^{-}$[13-15]. Пик при $190 \mathrm{~K}$ с энергией активации $0.38 \mathrm{eV}$ принадлежит гидроксиду бериллия. Размытый пик с максимумом при $\sim 310 \mathrm{~K}$ с энергией активации $0.8 \mathrm{eV}$ обусловлен термостимулированной люминесценцией хемосорбированного кислорода и других кислородсодержащих групп $\left(\mathrm{OH}^{-}\right)$на поверхностных электронных $F^{+}$и $F$-центрах. При идентификации пиков РТЛ мы основывались на экспериментальных данных о взаимодействии воды с поверхностью металлов из работ $[8,18,19]$. В таблице приведены люминесцентные параметры нанооксидных пленок на поверхности алюминия и бериллия.

Наблюдаемые особенности проявления многокомпонентной структуры кислородного пика РТЛ в областях 100-250 и 90-350 K (при сравнительно толстых неод- нородных нанооксидных пленках алюминия и бериллия) связаны как с неоднородностью самих дырочных центров, так и с тем, что радиационно-адсорбированный кислород может находиться на поверхности в различных состояниях $\left(\mathrm{O}_{\mathrm{ads}}^{-2}, \mathrm{O}_{\mathrm{ads}}^{2-}, \mathrm{OH}_{\mathrm{ads}}^{-}\right.$и т.д.). Следует отметить, что с утолщением оксидной пленки радиационно стимулированная адсорбция кислорода происходит уже на границах $\mathrm{Al} / \mathrm{Al}_{2} \mathrm{O}_{3}$ и $\mathrm{Be} / \mathrm{BeO}$. Поэтому рост интенсивности кислородного пика РТЛ с ростом толщины оксидной пленки следует связывать с увеличением плотности поверхностных дефектных состояний в приповерхностном

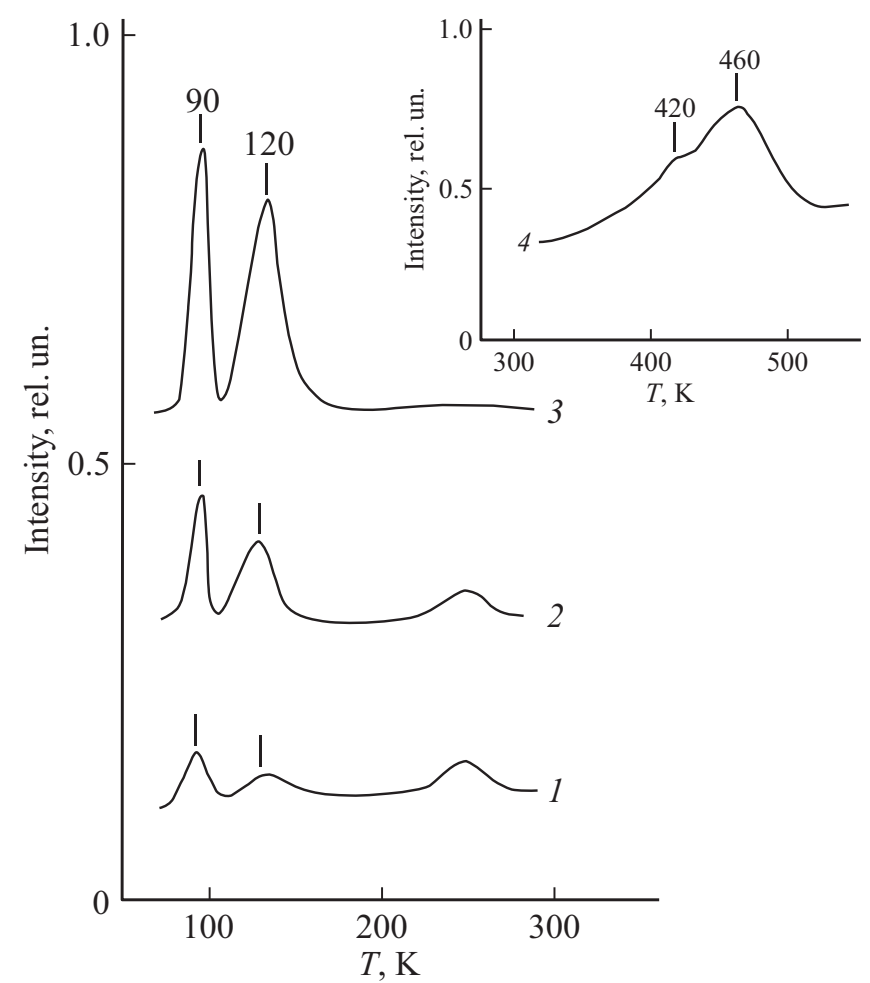

Рис. 2. Изменение кривых РТЛ оксидных пленок в зависимости от времени контакта бериллия с водой при радиационном окислении Be: $30 \mathrm{~min}(1), 5 \mathrm{~h}$ (2), $25 \mathrm{~h}$ (3), 25 days (вставка, 4). $T=300 \mathrm{~K}, d \Phi_{\gamma} / d t=1.03 \mathrm{~Gy} \cdot \mathrm{s}^{-1}$. 


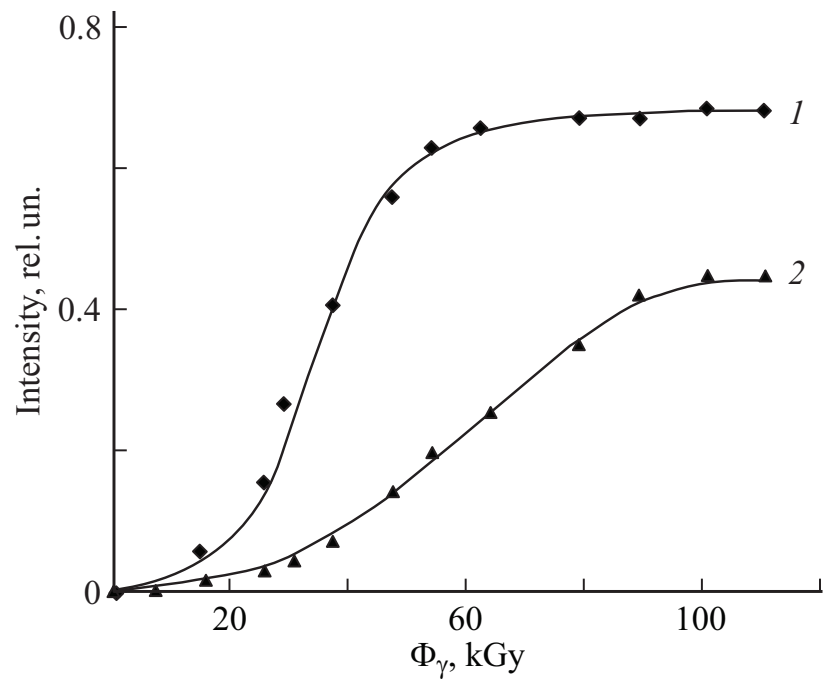

Рис. 3. Зависимости интенсивностей пиков РТЛ с максимумами при 170 и $90 \mathrm{~K}$ от поглощенной дозы $\gamma$-облучения в системах $\mathrm{Al} / \mathrm{ads} . \mathrm{H}_{2} \mathrm{O}$ и Be/ads. $\mathrm{H}_{2} \mathrm{O}$ при радиационном окислении $\mathrm{Al}$ (1) и $\mathrm{Be}(2)$ при комнатной температуре.

оксидном слое $\mathrm{Al}_{2} \mathrm{O}_{3}$ и $\mathrm{BeO}$, а значит, и с ростом вероятности адсорбции кислорода на этих центрах.

Кинетические кривые радиационного окисления алюминия и бериллия в присутствии воды, т. е. зависимости интенсивностей $(I)$ пиков РТЛ хемосорбированного кислорода при температурах 170 и $90 \mathrm{~K}$ от поглощенной дозы $\gamma$-облучения в системах $\mathrm{Al}(\mathrm{Be}) / \mathrm{ads} \mathrm{H}_{2} \mathrm{O}$, показывают, что кривые состоят из (i) участков в области малых доз, характеризующих начальный индукционной период, связанный с „залечиванием“ биографических дефектов в металле, (ii) из линейных областей, обусловленных в основном образованием и генерацией радиационноактивных поверхностных центров с последующим взаимодействием их с кислородом, вследствие которого и формируется нанооксидная пленка, и наконец, (iii) из стационарной области насыщения (рис. 3) [9,10,20].

Наблюдаемая кинетическая закономерность образования хемосорбированного кислородно-оксидного слоя полностью согласуется с результатами работ по оптическому исследованию накопления радиационных дефектов в $\gamma$-облученных оксидах алюминия и бериллия $[21,22]$ и указывает на хемосорбционную пассивацию металла. При этом поглощенная доза, соответствующая началу хемосорбционной пассивации алюминия (рис. 3, кривая 1) и бериллия (рис. 3, кривая 2), составляют $\Phi_{\gamma} \geq 55$ и $\Phi_{\gamma} \geq 85 \mathrm{kGy}$ соответственно. Скорость окисления, определяемая по линейным областям в случае алюминия в $\sim 3$ раза превышает скорости окисления бериллия. Кинетика радиационного окисления показывает, что в рассматриваемой области поглощенной дозы осуществляется классическая пассивация поверхностным нанооксидным слоем, регулируемая диффузией.

Оксидная пленка будет препятствовать проникновению промежуточных релаксирующих продуктов радио- лиза $\mathrm{H}_{2} \mathrm{O}$ в реакционное пространство и таким образом тормозить дальнейший ее рост. Сравнительный анализ данных РТЛ исследований показывает, что при окислении алюминия и бериллия в водной среде при комнатной температуре происходит наноструктурирование поверхности этих металлов, сопровождающееся образованием и формированием нанооксидных пленок. В таблице приведены люминесцентные (РТЛ) параметры нанооксидных пленок алюминия и бериллия.

При гетерогенном радиолизе воды в контакте с металлом (алюминием и бериллием) воздействию $\gamma$-квантов подвергаются как вода, так и бериллий. Поскольку металлы представляют собой остов из положительных ионов, погруженный в электронный газ, то возбуждение и ионизацию в них создают только дефекты, возникающие при упругих соударениях. Такими дефектными центрами являются радиационно-индуцированные активные поверхностные состояния (ионы, локализованные заряды, анионные вакансии, радиационные дефекты типа пар Френкеля и т.д.). Образование радиационных дефектов $\left(\mathrm{Me}^{+}\right)$схематически можно представить в виде

$$
\mathrm{Me} \stackrel{\gamma}{\longrightarrow} \mathrm{Me}^{+}+e^{-} \text {. }
$$

На радиационно-активных центрах происходит адсорбция молекул воды с образованием комплексов $\left(\mathrm{Me}^{+} \ldots \mathrm{H}_{2} \mathrm{O}\right)$ :

$$
\mathrm{Me}^{+}+\mathrm{H}_{2} \mathrm{O} \rightarrow \mathrm{Me}^{+} \ldots \mathrm{H}_{2} \mathrm{O} .
$$

В результате каскада электронных процессов, происходящих в металле, из него выходит вторичное электронное излучение (1), т.е. в контактирующую среду эмитируют дельта-электроны [23]. При этом основную роль играют тепловые электроны, возникающие в результате упругих столкновений электронов первого поколений $\left(e^{-}\right)$с атомами металла при эффекте Комптона. Поскольку эффективное сечение комптоновского рассеяния внутри бериллия по сравнению с сечениями фотоэффекта и образования электронпозитронной пары на порядок больше, можно не учитывать эти процессы [1-3,23]. При рекомбинации комплексов Ме... $\mathrm{H}_{2} \mathrm{O}$ с тепловыми электронами происходит возбуждение

$$
\mathrm{Me}^{+} \ldots \mathrm{H}_{2} \mathrm{O}+e^{-} \rightarrow \mathrm{Me} \ldots \mathrm{H}_{2} \mathrm{O}^{*}
$$

а затем распад молекул воды по механизму

$$
\mathrm{Me}^{+} \ldots \mathrm{H}_{2} \mathrm{O} \rightarrow \mathrm{Me}+\mathrm{H}+\mathrm{OH} .
$$

Промежуточные продукты радиолиза могут взаимодействовать с поверхностноактивными состояниями Ме:

$$
\begin{gathered}
>\mathrm{Me}+\mathrm{H} \rightarrow \mathrm{MeH}, \\
>\mathrm{Me}+\mathrm{OH} \rightarrow \mathrm{MeOH},
\end{gathered}
$$

т. е. образуются гидриды и гидроксиды бериллия. 
Образование поверхностных гидроксилов подтверждается появлением полос поглощения валентных колебаний групп ОН в области $3600-3460 \mathrm{~cm}^{-1}$, а появление в ИК спектре полос в области 2000-1600 $\mathrm{cm}^{-1}$ можно рассматривать как доказательство образования на поверхности металла связи $\mathrm{Me}-\mathrm{H}$ типа $\mathrm{Al}(\mathrm{Be})-\mathrm{H}$ и поверхностных гидридов алюминия и бериллия $\mathrm{Al}(\mathrm{Be}) \mathrm{H}_{2}[24,25]$.

Другими продуктами радиолиза воды в системе $\mathrm{MeO}-\mathrm{H}_{2} \mathrm{O}$ являются:

$$
\begin{aligned}
& \mathrm{H}+\mathrm{H} \rightarrow \mathrm{H}_{2} \quad \text { (молекулярный водород), } \\
& \mathrm{OH}+\mathrm{OH} \rightarrow \mathrm{H}_{2} \mathrm{O}_{2} \quad \text { (перекись водорода), } \\
& \mathrm{O}+\mathrm{O} \rightarrow \mathrm{O}_{2} \quad \text { (молекулярный кислород). }
\end{aligned}
$$

Образование на поверхности адсорбированного состояния молекулярного $\mathrm{O}_{2}^{-}$:

$$
\begin{gathered}
\mathrm{O}_{2}+e^{-} \rightarrow \mathrm{O}_{2}^{-}, \\
\mathrm{O}_{2}^{-}+{ }^{+} \mathrm{Me}\langle\rightarrow\rangle \mathrm{Me}^{+} \ldots \mathrm{O}_{2}^{-},
\end{gathered}
$$

и кислородных дырок $\mathrm{O}^{-}$:

$$
\mathrm{O}+\mathrm{Me}^{+} \rightarrow \mathrm{MeO}^{-}
$$

подтверждается измерениями РТЛ и ИК данными. Согласно $[9,10]$, полоса поглощения с максимумом при $1250 \mathrm{~cm}^{-1}$ относится к адсорбированному кислороду $\mathrm{O}_{2 \mathrm{ads}}^{-}$.

Образовавшиеся по (12) дырочные центры мигрируют вовнутрь и взаимодействуют с объемными атомами бериллия.

\section{Заключение}

Методом РТЛ изучено окисление алюминия и бериллия в контакте с водой при комнатной температуре и при радиационном воздействии. Зарегистрированы пики РТЛ в областях $100-250 \mathrm{~K}$ (для алюминия) и $80-300 \mathrm{~K}$ (для бериллия) с энергиями активации $0.38-0.65 \mathrm{eV}$, которые связаны с термостимулированной адсорбои хемолюминесценцией кислорода и содержащих его групп на поверхностно-локализованных центрах при $\gamma$ облучении. Изучена кинетика радиационного окисления алюминия и бериллия и выявлена его радиационнохемосорбционная пассивация при поглощенных дозах $\Phi_{\gamma} \geq 55$ и $\Phi_{\gamma} \geq 85 \mathrm{kGy}$. Показано, что при радиационном окислении $\mathrm{Al}$ и $\mathrm{Be}$ в контакте с водой на поверхности металлов в рассматриваемой области поглощенной дозы $\left(\Phi_{\gamma}=0.5-120 \mathrm{kGy}\right)$ при комнатной температуре формируется оксидная наноструктура, которая в дальнейшем играет определяющую роль в радиационных процессах. Обсужден возможный механизм процесса радиационного окисления.

\section{Список литературы}

[1] Герасимов В.В. Коррозия реакторных материалов. М.: Атомиздат, 1980. $185 \mathrm{c.}$

[2] Конобеевский C.T. Действие облучения на материалы. Введение в радиационное материаловедение. М.: Атомиздат, 1980. $401 \mathrm{c}$.

[3] Седов В.М., Нечаев А.Ф., Петрик И.Г. и др. Радиационная химия теплоносителей ядерных установок. Межфазные процессы. Л.: ЛТИ им. Ленсовета, 1987. 58 с.

[4] Платонов П.А., Турсунов И.Е., Левит В.И. // Вопросы атомной науки и техники. Физика радиационных повреждений и радиационное материаловедение.1987. В. 2 (40). C. 65.

[5] Кузнецов А.М. // Соросовский образовательный журнал. 2000. T. 6. № 5. C. 45.

[6] Gadzhieva N.N. // J. Appl. Spectr. 2005. V. 72. P. 471.

[7] Гаджиева Н.Н. // Физика и химия обработки материалов. 2010. № 3. C. 34.

[8] Gadzhieva N.N., Garibov A.A., Ismailov Sh.S., Nurmamedova F.N. // Int. J. Mater. Sci. Appl. 2014. V. 3. P. 16.

[9] Гаджиева Н.Н., Нурмамедова Ф.Н. // Журн. физ. химии. 2012. T. 86. № 9. C. 1.

[10] Гаджиева Н.Н., Гарибов А.А., Исмаилов Ш.С. // ВАНТ. Сер. физика радиационных повреждений и радиационное материаловедение. 2007. № 6. С. 36.

[11] Пикаев А.К. // Современная радиационная химия. Радиолиз газов и жидкостей. М.: Наука, 1986. С. 5.

[12] Кулешов В.Н., Никольский В.Г. Радиотермолюминесценция полимеров. М.: Наука, 1991. 223 с.

[13] Strohmeier B.R. // Surf. Interf. Anal. 1990. V. 15. P. 51.

[14] Кузнецов В.Н., Лисаченко А.А. // Кинетика и катализ. 1991. T. 32. В. 1. C. 222.

[15] Климовский А.О., Лисаченко А.А. // Хим. физ. 1987. Т. 6. № 7. C. 969.

[16] Kasemo B. // Phys. Rev. Lett. 1974. V. 32. N 20. P. 1114.

[17] Rosenwaks S., Steele R.E., Broida H.P. // J. Chem. Phys. 1975. V. 63. P. 1963.

[18] Gadzhieva N.N., Nurmamedova F.N. // Protection of Metals and Phys. Chem. of Surface. 2012. V. 48. P. 419.

[19] Гаджиева Н.Н., Гарибов А.А., Нурмамедова Ф.Н., Исмаилов Ш.С. // Вопросы атомной науки и техники. 2012. № 5. T. 81. C. 21.

[20] Кортов В.С., Мильман И.И. // Изв. вузов. Физика. 1996. B. 11 . C. 145.

[21] Hara M., Domen K., Onishi T., Nozoye H. // J. Phys. Chem. 1991. V. 95. P. 6.

[22] Hara M., Domen K., Kato M. et al. // J. Chem. Soc. Chem. Commun. 1990. N 23. P. 1717.

[23] Аккерман А.Ф., Грудский М.Я., Смирнов Б.Б. Вторичное электронное излучение в твердых телах под действием $\gamma$ квантов. М.: Энергоиздат, 1986. 168 с.

[24] Давыдов Д.А. // Вопросы атомной науки и техники. 2010. B. 2. C. 39.

[25] Давыдов Д.А., Бирюков А.Ю., Холопова О.В., Морковников В.Е., Мельникова С.Н., Сорокин С.И., Колбасов Б.Н. Электронный ресурс. Режим доступа. http://iterru.ru/vant.2006.P.2. 